\title{
Integrating Medical Economic Perspectives through Information Literacy in a Biomedical Clinical Immersion Design Course (Work in Progress)
}

\section{Mr. Alexander J. Carroll, North Carolina State University}

Alex Carroll is the Research Librarian for Engineering and Biotechnology at the NCSU Libraries, where he works with the College of Textiles and the College of Engineering in areas that intersect with human and animal health. He has an M.S. from the School of Information and Library Science at the University of North Carolina at Chapel Hill, and a B.A. from James Madison University.

\section{Dr. Andrew J. DiMeo Sr., UNC \& North Carolina State University}

Andrew started in the NYC Motion Picture Industry before transitioning into his 15+ years in Biomedical Product Development. Today he teaches product innovation in Biomedical Engineering (BME) at UNC $\&$ NC State where he is an Associate Professor. Andrew's courses resulted in multiple startups including Novocor Medical Systems, Augment Medical, Contour Surgical, 410 Medical, and MEDIC. He is founder and former director of the NC Medical Device Organization, which became an NC Biotech Center of Innovation. He was co-founder and VP Business Development for Gilero, an RTP based service company. Andrew worked for Alaris Medical Systems (now BD's CareFusion) as a design engineer and project manager. He is Business Advisor and Speaker for the Wallace H. Coulter Foundation, Director of Duke NeuroInnovations, and on the planning team for BME IDEA. He holds a BS in Physics, English Literature, and Secondary Education from UNC Charlotte, an MS in BME from UNC Chapel Hill's Medical School, and a Ph.D. from the UNC/NCSU BME Department. Andrew has two children, 15-year-old daughter Virginia Elaine and 13-year-old son Andrew, Jr. His wife, Abigail Kent, is a nurse at the NC State Highway Patrol.

\section{Dr. Hatice O. Ozturk, North Carolina State University}

Dr. Hatice Ozturk is a Teaching Associate Professor at North Carolina State University, Departments of Electrical and Computer Engineering and Biomedical Engineering. She is the coordinator of assessment and accreditation in both departments. Her engineering education area of research is development of instructional technologies for successful math to engineering transition. She also collaborates with faculty in Women's and Gender Studies to study the impacts of interventions designed to enrich the experience of women in engineering.

\section{Mr. James McCall, North Carolina State University}

James McCall is currently a BME PhD student at North Carolina State University. 


\section{Works in Progress: Integrating Clinical and Entrepreneurial Information Literacy into the Biomedical Engineering Design Curriculum}

The landscape of today's Biomedical Product Development Industry calls for a diverse set of skills beyond the typical engineering fundamentals. The current Hospital Value-Based Purchasing environment driven by the Department of Health and Human Services Centers for Medicare \& Medicaid Services (CMS) measure all new products by their ability to improve clinical outcomes, increase patient satisfaction, and lower the cost of care. ${ }^{1}$ Preparing students to become leaders in the Biomedical Engineering (BME) industry therefore must include an understanding of health economics and a broad view of the continuum of care and overall impact of care. The proposed changes to Accreditation Board for Engineering and Technology, Inc.'s (ABET) Criterion 3 signals the changing demands of the modern medical device product development environment. Under the proposed changes, accredited BME programs will be expected to develop diverse teams of engineers that are not only comfortable in the clinical environment, but also "recognize ethical and professional responsibilities in engineering situations" and have the ability to identify "the ongoing need for additional knowledge and locate, evaluate, integrate, and apply this knowledge appropriately."”

For many engineering disciplines, teaching students how to find and use journal articles, patents, and standards ensures that they will have a relatively complete understanding of the professional information environment. ${ }^{3}$ However, BME students entering the workforce increasingly need to be well versed in finding and utilizing additional sources of information, such as clinical data and medical bill coding. ${ }^{4}$ Recognizing this gap in the curriculum, in the spring of 2016 several instructors from the North Carolina State University Department of Biomedical Engineering began partnering with the North Carolina State University Libraries to implement a substantially more rigorous information literacy training program. In this overhauled instructional design, students now receive training during their junior design course on finding: epidemiology data and disease state information; peer-reviewed articles from scholarly journals; patents; and business intelligence information on competitor medical device companies. During their senior design course, students receive training on finding: standards; legal information; FDA regulatory information; and reimbursement and medical billing information. This training is delivered via guest lectures from an engineering librarian, who in addition to explaining how and where to find these types of information also teaches students how to use information ethically. Students receiving this updated information literacy training are required in the documentation that accompanies their design projects to include relevant information from these different data sources, and to synthesize the information they find to justify the potential marketability of their product while considering CMS value-based criteria.

\section{Course Descriptions}

BME 352 (Junior Design) is a one-semester required course and prerequisite to Senior Design. The course is split between hands on manufacturing skills and product development skills to prepare students for Senior Design. Topics covered in Junior Design include lab safety, keeping a scientific notebook, need statement development, problem identification, needs filtering, product validation, product specifications, brainstorming, introduction to hospital shadowing, 
working in teams, design for manufacturing, document controls, market analysis, intellectual property basics, library skills, regulatory basics, healthcare economics, and project management.

BME 451 and 452 (Senior Design) is a two-semester required course to prepare students for the workplace and/or graduate studies. The course uses a Design Control Process based on the FDA's Quality System Regulations to move student teams from a Needs Assessment through Product Development and Testing. Each team progresses through a minimum of 4 phases while maintaining a Design History File. The aim of the courses is to provide the opportunity for senior biomedical engineering students to both integrate and continue to grow their engineering knowledge by accomplishing "real world" engineering design projects. In addition to project activity, students are provided educational resources addressing ethics and professionalism, manufacturing and standards, and intellectual property. BME 451 encompasses the Project Proposal and Design Concepts, including: individual pre-proposals, team proposals, project planning, scheduling, needs assessment, product requirements, competitive landscape and patent review, business risks, design concepts, and phase reviews. BME 452 is a continuation of BME 451 moving from Proposal and Concepts into Manufacturing, Prototyping, and Testing. The deliverables in this course include: detailed manufacturing specifications, biomaterials review, supplier identification, product feasibility, issues tracking, manufacturing planning, bill of materials, product risks, qualification protocol, IP disclosure, process validation planning, regulatory review, design history file audit, lessons learned, and phase reviews.

\section{Methodology}

To measure the effects of the updated information literacy training for these courses, the investigators are conducting a cohort study. Our control group is drawn from a representative sample of student assignments that were completed prior to the implementation of the updated information literacy training program. While students in the control group received a single lecture on finding articles and patents during BME 451, they did not receive training on how to find hospital-based value purchasing information. We define these types of sources as including, but not limited to: CMS coverage, Current Procedural Terminology (CPT) codes, 510(k)s, FDA Premarket Approvals and Post-Approval Studies, product recalls, and medical device litigation, among others. Students in Experimental Group One (EX1) are drawn from a representative sample from the BME Class of 2017. Students in EX1 received training on finding articles and patents during their junior design course (BME 352), as well as specific training on how to find hospital-based value purchasing information during their senior design course (BME 451). However, students in EX1 were not required to use this information in any assignments. Students in Experimental Group Two (EX2) are drawn from a representative sample from the BME Class of 2018. Students in EX2 received the same training as students in EX1; however, their assignments explicitly require them to utilize the information sources they are being introduced to in these training interventions. Students in EX2 will also be required to send a member of their design team to meet with a librarian to discuss their information seeking strategies, as well as any barriers they are encountering during this process.

We hypothesize that increasing the extent and frequency of instructional interventions on information seeking will increase the quality and variety of information that students consult during their design projects. We further hypothesize that the students' extent of information use 
will correlate with overall success of the design project. Lastly, to determine whether or not instructor requirements were more determinative than the instructional intervention, we updated some of the assignments to explicitly require the EX2 cohort to use hospital-based value purchasing information sources. Table 1 presents a visual breakdown that explains the training and assignment differences between the groups.

Table 1. Cohort Descriptions

\begin{tabular}{|l|l|l|l|l|}
\hline $\begin{array}{l}\text { Cohort } \\
\text { Title }\end{array}$ & $\begin{array}{l}\text { BME 352 } \\
\text { Intervention? }\end{array}$ & $\begin{array}{l}\text { BME 451 } \\
\text { Intervention? }\end{array}$ & $\begin{array}{l}\text { Info Use } \\
\text { Requirements }\end{array}$ & $\begin{array}{l}\text { Required Meeting } \\
\text { with Librarian }\end{array}$ \\
\hline Control & No & Yes & No & No \\
\hline EX1 & Yes & Yes & No & No \\
\hline EX2 & Yes & Yes & Yes & Yes \\
\hline
\end{tabular}

To assess the effectiveness of this new instructional intervention, rubrics (see Appendix A-D) are being used to measure several aspects of students' utilization of information in their documentation, such as the extent of information use, selection of appropriate resources, ethical use of information, and the effectiveness of use, among others. Performance in information use, as measured by rubrics, will be correlated with the grade student teams received on their overall design project to determine if a relationship exists between extent of information use and overall performance. Other outcomes of interest that will be used as points of comparison between the groups will include design competition participation rates, performance in end of semester presentations, as well as compliance with assigned deadlines for project components. For example, we will measure teams' participation rate in the DEBUT challenge. ${ }^{5}$ The control cohort had a participation rate of approximately 8 percent $(n=12)$, which will be used as a baseline for comparison for each experimental group. In addition to tracking participation rate, we will compare each cohort's contest submissions by measuring their projects' achievement of the following learning outcomes: 1) justify the problem addressed by explaining the impact on potential users and clinical care; 2) evaluate the design concepts for market potential, economic feasibility, and patentability; 3 ) design the product as a creative response to a need, the functionality of which is driven by people; 4) apply engineering knowledge and skills to build a working prototype.

\section{Conclusion}

Our protocol, as approved by our Institutional Review Broad, prohibits us from analyzing student learning results prior to each cohort's graduation, so we are unable to share our preliminary data at this time. The accompanying poster will share the authors' preliminary findings based on the results from the control group as well as EX1. It will also discuss lessons learned from this long-term collaboration between an engineering department and a university library. 


\section{Appendix A: BME 352 EX 1 Relevant Research Rubric}

\begin{tabular}{|c|}
\hline \begin{tabular}{ll} 
& \multicolumn{2}{c}{ Use of Deliverable Format (Max 10pts) } \\
- & Names and Dates Included \\
- & Signature Blocks \\
- & Revision Table \\
- & Heading Styles
\end{tabular} \\
\hline 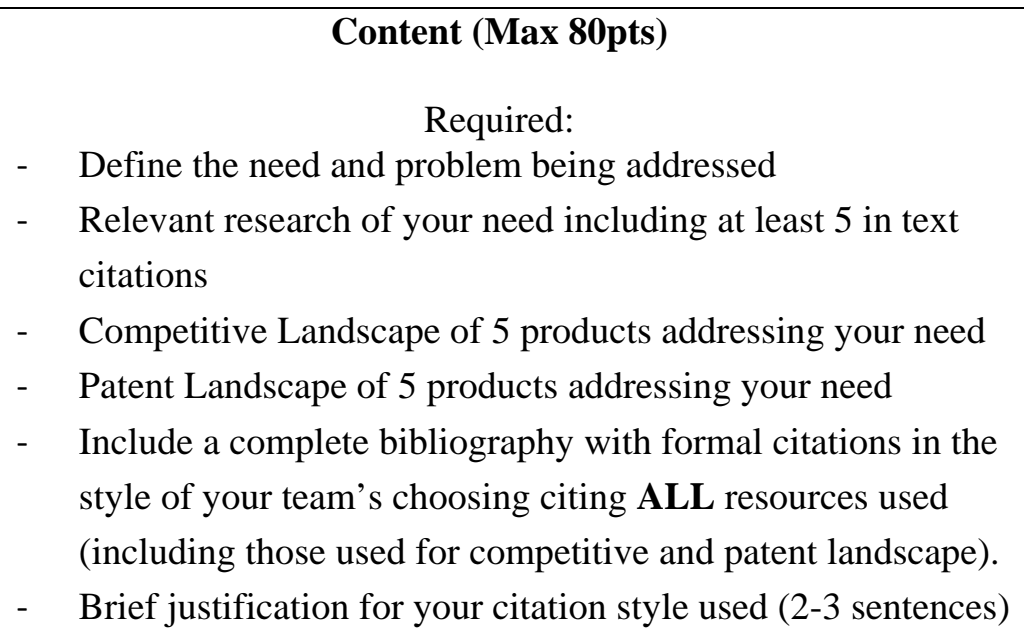 \\
\hline \begin{tabular}{ll} 
& \multicolumn{1}{c}{ Quality of Work (Max 10pts) } \\
- & Thorough analysis of your need. \\
- & Detailed descriptions of competitors and patents \\
- & All citations are properly formatted
\end{tabular} \\
\hline
\end{tabular}




\section{Appendix B: BME 352 EX 2 Relevant Research Rubric}

\begin{tabular}{|c|c|}
\hline \begin{tabular}{ll} 
& \multicolumn{1}{c}{ Use of Deliverable Format (Max 10pts) } \\
- & Names and Dates Included \\
- & Signature Blocks \\
- & Revision Table \\
- & Heading Styles
\end{tabular} & \\
\hline $\begin{array}{l}\text { Content (Max 80pts) } \\
\text { Required: } \\
\text { - } \quad \text { A narrative introduction that define the need and problem } \\
\text { being addressed } \\
\text { - } \quad \text { Brief justification for your citation style used (2-3 sentences) } \\
\text { - } \text { A complete annotated bibliography with at least } 10 \text { formal } \\
\text { citations in the style of your team's choosing citing ALL } \\
\text { resources used. } \\
\text { Each annotation includes: } \\
\text { o What type of source it is (epidemiological } \\
\text { information, journal article, patent, or company } \\
\text { information). } \\
\text { o Where you found the source (i.e., database searched). } \\
\text { o A one sentence summary of the information contained } \\
\text { in the source. } \\
\text { o A one sentence explanation of relevance of the } \\
\text { information to your device. } \\
\text { Of the } 10 \text { sources cited in the annotated bibliography, one } \\
\text { must be epidemiological information, two journal articles, two } \\
\text { company profiles / business information, two patents, and } \\
\text { three of your choice }\end{array}$ & \\
\hline \begin{tabular}{ll}
\multicolumn{1}{c}{ Quality of Work (Max 10pts) } \\
- $\quad$ Thorough analysis of your need. \\
- $\quad$ Detailed descriptions of competitors and patents \\
- $\quad$ All citations are properly formatted
\end{tabular} & \\
\hline
\end{tabular}




\section{Appendix C: BME 451 EX 1 Competitive Landscape and Patent Review Rubric}

\begin{tabular}{|c|c|c|}
\hline Category & Points & Grade \\
\hline Quality of Work & 25 & \\
\hline $\begin{array}{l}\text { All sections of the deliverable have been adequately filled out: } \\
\text { Abstract } \\
\text { - }\end{array}$ & 65 & \\
\hline $\begin{array}{l}\text { Formatting } \\
\begin{array}{l}\text { - } \\
\text { - }\end{array} \text { Deleting highlighted areas } \\
\text { - Single Spaced, } 1 \text { ” Margins, 12-point Times New Roman font } \\
\text { - } \text { Proper placement of name or date locations } \\
\text { - Table of Contents reflects section names and page numbers } \\
\text { - } \text { No sponsor signature } \\
\text { Spelling/grammar }\end{array}$ & 10 & \\
\hline
\end{tabular}




\section{Appendix D: BME 451 EX 2 Competitive Landscape and Patent Review Rubric}

\begin{tabular}{|c|c|c|}
\hline Category & Points & Grade \\
\hline Quality of Work & 25 & \\
\hline $\begin{array}{l}\text { Content } \\
\text { All sections of the deliverable have been adequately filled out: } \\
\text { - } \\
\text { - }\end{array}$ & 65 & \\
\hline $\begin{array}{l}\text { Formatting } \\
\begin{array}{l}\text { - } \\
\text { - }\end{array} \text { Dilename follows format: < T\#\#-D13-Comp-and-IP-Landscape.pdf> } \\
\text { - Single Spaced, 1” Margins, 12-point Times New Roman font } \\
\text { - } \text { Proper placement of name or date locations } \\
\text { - } \text { Table of Contents reflects section names and page numbers } \\
\text { - Spelling/grammar }\end{array}$ & 10 & \\
\hline
\end{tabular}




\section{References}

1. Centers for Medicare \& Medicaid Services, "Hospital Value-Based Purchasing” (Department of Health \& Human Services, September 2015), https://www.cms.gov/Outreach-and-Education/Medicare-LearningNetwork-MLN/MLNProducts/downloads/Hospital_VBPurchasing_Fact_Sheet_ICN907664.pdf.

2. Accreditation Board for Engineering and Technology, Inc., "Criteria for Accrediting Engineering Programs, 2016 - 2017,” accessed February 2, 2017, http://www.abet.org/accreditation/accreditationcriteria/criteria-for-accrediting-engineering-programs-2016-2017/.

3. Rachel Callison, Dan Budny, and Kate Thomes, "Library Research Project for First-Year Engineering Students: Results from Collaboration by Teaching and Library Faculty,” The Reference Librarian 43, no. 89-90 (2005): 93-106; H. Nerz and Lisa Bullard, "The Literate Engineer: Infusing Information Literacy Skills throughout an Engineering Curriculum,” in Proceedings of the 2006 American Society for Engineering Education Annual Conference \& Exposition, 2006; Honora F. Nerz and Suzanne T. Weiner, "Information Competencies: A Strategic Approach," in Proceedings of the 2001 American Society for Engineering Annual Conference \& Exposition. Session, vol. 2241, 2001, http://depts.washington.edu/englib/eld/fulltext/00510_2001.pdf; Craig Milne and Jennifer A. Thomas, "Are Your Foundations Sound? Information Literacy and the Building of Holistic Professional Practitioners,” 2008, http://eprints.qut.edu.au/16899/; Eleanor M. Smith, “Developing an Information Skills Curriculum for the Sciences,” Issues in Science and Technology Librarianship 37, no. 1 (2003), http://www.istl.org/03-Spring/article8.html; John B. Napp, "Survey of Library Services at Engineering News Record's Top 500 Design Firms: Implications for Engineering Education,” Journal of Engineering Education 93, no. 3 (July 2004): 247-52.

4. Thomas K. Grose, “Invention Roulette,” ASEE Prism 26, no. 1 (2016): 36-39.

5. National Institutes of Health, "Design by Biomedical Undergraduate Teams (DEBUT) Challenge,” National Institute of Biomedical Imaging and Bioengineering, May 22, 2013, https://www.nibib.nih.gov/training-careers/undergraduate-graduate/design-biomedical-undergraduateteams-debut-challenge. 